\title{
OPQPey) (Anaesthesiology \\ A COMPARATIVE STUDY OF HAEMODYNAMIC AND RECOVERY \\ CHARACTERISTICS OF DESFLURANE VERSUS SEVOFLURANE IN PATIENTS UNDER GOING LAPAROSCOPIC SURGERY
}

\section{Dr. Ankita Bhensdadia \\ Dr. Namrata Shah*}

Third Year Resident, Department Of Anaesthesiology, BJ Medical College, Ahmedabad.

Assistant Professor, Department Of Anaesthesiology, BJ Medical College, Ahmedabad. *Corresponding Author

\section{Dr. Rajan Patel}

Senior Resident, Department Of Anaesthesiology, BJ Medical College, Ahmedabad. pneumoperitoneum. Therefore, anesthesiologist must choose anesthetic agent which provide hemodynamic stability and rapid recovery. Inhaled anesthetics with low blood: gas partition contributes to faster induction and emergence from anesthesia. Both Desflurane and Sevoflurane have low blood: gas partition coefficient 0.42 and 0.65 respectively. We conducted the study to know which of these two agents contributes to faster recovery and hemodynamics. CONCLUSION- Desflurane and Sevoflurane provide stable intraoperative hemodynamic, however early and intermediate recovery is significantly faster in Desflurane group than Sevoflurane group.

KEYWORDS : Laparoscopy; Sevoflurane ; Desflurane ; Hemodynamics ; Recovery

\section{INTRODUCTION}

Laparoscopic surgery is minimal invasive surgery that is associated with several advantages like smaller scar, reduced bleeding, reduced postoperative pain and infection which contributes to shorter hospital stay. $\mathrm{CO} 2$ insufflation will cause increased abdominal pressure and hypercapnia which may contribute to undesirable hemodynamic changes. Goals of any anesthetic technique are smooth onset of action, adequate intraoperative analgesia and amnesia, good surgical condition, rapid recovery and minimal adverse effects Use of volatile anesthetics agents that are rapidly eliminated with minimal metabolic breakdown facilitate a faster recovery after general anesthesia. Sevoflurane and Desflurane are volatile anesthetics that has low blood-gas partition coefficient of 0.65 and 0.42 respectively at 37 C., and this has been shown to result in a rapid induction and a rapid recovery from anesthesia.

\section{AIMS OF STUDY}

The aim of this study was to compare and evaluate the intraoperative hemodynamic and recovery characteristics after anaesthesia with Sevoflurane \& Desflurane for patients undergoing laparoscopic surgeries.

\section{MATERIAL AND METHODS}

In our prospective, observational study we took approval by hospital ethics committee \& a written, informed consent from patient's relatives was taken. Sixty patients of ASA physical status I-II-III, aged $>12$ years scheduled to undergo laparoscopic cholecystectomy/ appendicectomy surgery under general anesthesia were selected for the study.

All the patients were pre-medicated with intravenous glycopyrrolate $0.004 \mathrm{mg} / \mathrm{kg}$., ondansetron $0.16 \mathrm{mg} / \mathrm{kg}$, fentanyl $2 \mu \mathrm{g} / \mathrm{kg}$. ECG, NIBP, $\mathrm{SpO}_{2}$ were monitored. Base line hemodynamic parameters were recorded. All the patients were pre-oxygenated with $100 \% \mathrm{O}_{2}$ for 3 mins. All the patients were induced with inj. Propofol $2.5 \mathrm{mg} / \mathrm{kg} \mathrm{IV}$. Patients were intubated with appropriate size of endotracheal cuffed tube after giving inj. Succinylcholine $2 \mathrm{mg} / \mathrm{kg}$ IV. Inj. Vecuronium $0.1 \mathrm{mg} / \mathrm{kg}$ as a muscle-relaxant .Patients were randomly allocated in two groups according to the type of inhalation agent used.

Group S (n=30): patients maintained on Sevoflurane (1-3\%), 50\% O2 $\& 50 \% \mathrm{~N} 2 \mathrm{O}$.

Group D (n=30): patients maintained on Desflurane (3-6\%), 50\% O2 $\& 50 \% \mathrm{~N} 2 \mathrm{O}$.
The inspired concentration of the volatile anesthetic was adjusted to maintain MAP within $20 \%$ of baseline values.

Intraoperative $\mathrm{SpO} 2$, NIBP, ECG, Heart rate, EtCO2 were monitored All the patients were ventilated by close circuit to maintain an EtCO2 of 30-35 mmHg. Rescue bolus dose of Fentanyl citrate $0.5 \mathrm{mcg} / \mathrm{kg}$ was administered to control acute hemodynamic changes not controlled by a $50 \%$ increase in inspired concentration of inhalation agent. The volatile anesthetic agent was discontinued at the end of the procedure and the Nitrous Oxide was discontinued after the last skin suture. Patients were reversed with inj. Glycopyrrolate $0.008 \mathrm{mg} / \mathrm{kg}$ and inj. Neostigmine $0.05 \mathrm{mg} / \mathrm{kg}$ IV. Inj. Diclofenac Sodium was administered $1.5-2 \mathrm{mg} / \mathrm{kg}$ Iv for postoperative pain relief.

Perioperative hemodynamic parameters were recorded. Postoperative recovery was assessed by the time from administration of reversal agent to response to painful stimuli, to eye opening, to verbal commands, stating name, stating the residential place, able to squeeze fingers, able to lift limb. Modified ALDRETE Score was recorded at the time of arrival to PACU. Time to achieve the ALDRETE score of 9 was also recorded.

\section{RESULT}

Both the study group were comparable with respect to Age, Weight, Gender, Duration of anesthesia, and duration of surgery $(p>0.05)$.

\section{- PULSE RATE (MIN)}

Preoperative pulse rate were comparable in both the groups. Even during the induction pulse rate did not differ in two groups. However, we observed increase in pulse rate during intubation in both the groups, this increase in pulse rate was within $20 \%$ of baseline value. Intra-operatively pulse rate did not differ in both the groups.

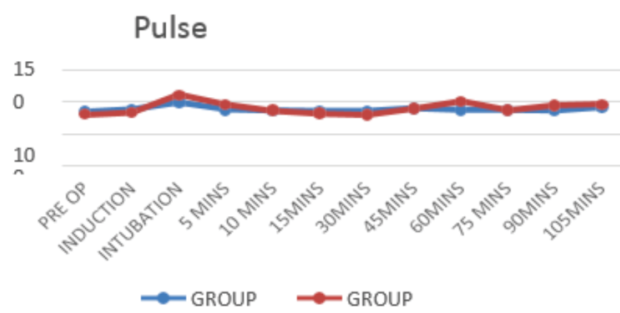

- BLOOD PRESSURE

Rise in blood pressure was observed after intubation. This rise was within $20 \%$ of baseline value in both groups. 


\begin{tabular}{|c|c|c|c|}
\hline \multicolumn{3}{|c|}{} \\
\hline $\begin{array}{c}\text { Respond to painful stimuli } \\
\text { (min) }\end{array}$ & $3.66 \pm 1.57$ & $6.5 \pm 1.23$ & 0.001 \\
\hline Respond Verbal Command & $4.9 \pm 1.86$ & $7.46 \pm 1.40$ & 0.005 \\
\hline Spontaneous Eye Opening & $5.53 \pm 2.14$ & $6.63 \pm 1.68$ & 0.039 \\
\hline Stating Name & $6.56 \pm 2.10$ & $10.26 \pm 1.36$ & 0.008 \\
\hline PLACE OF STAY & $6.78 \pm 2.03$ & $11.04 \pm 1.44$ & 0.005 \\
\hline SQUEEZE FINGERS & $7.37 \pm 2.12$ & $11.59 \pm 1.47$ & 0.001 \\
\hline Limb Lift & $7.6 \pm 2.43$ & $12.13 \pm 1.56$ & 0.008 \\
\hline $\begin{array}{c}\text { MODIFIED ALDRETE } \\
\text { SCORE(Arrival) }\end{array}$ & $7.2 \pm 1.04$ & $6.43 \pm 0.88$ & 0.04 \\
\hline $\begin{array}{c}\text { TIME TO ACHIEVE } \\
\text { MODIFEIED ALDERETE } \\
\text { SCORE OF NINE }\end{array}$ & $9.14 \pm 0.30$ & $10.17 \pm 0.55$ & 0.009 \\
\hline
\end{tabular}

The time to recovery of parameters like response to painful stimuli, respond to verbal command, spontaneous eye opening, stating name and place of stay, squeezing fingers and limb lifting are significantly shorter in group $\mathrm{D}$ than group $\mathrm{S}$. Patients in group $\mathrm{D}$ were responding to verbal command at an average $4.9 \mathrm{~min}$ as compared to $7.46 \mathrm{~min}$ in sevoflurane group.

MODIFIED ALDRETE SCORE at the time of arrival at the PACU was comparable in both the groups. Sevoflurane (6.43) group desflurane (7.2) group. Time to achieve MODIFIED ALDRETE SCORE of 9 was faster in desflurane (9.14) group then sevoflurane (10.17) group. $\mathrm{p}<0.05$, the difference is statistically significant.

\section{COMPLICATIONS:}

Incidence of complications like nausea, vomiting, drowsiness, respiratory distress,sore throat was similar in both the groups. Thus, the difference is clinically insignificant and $\mathrm{p}>0.05$.

\section{DISCUSSION}

Inhaled anesthetics with low blood: gas partition contributes to faster induction and emergence from anesthesia. Both Desflurane and sevoflurane has low blood: gas partition coefficient 0.42 and 0.65 respectively. We conducted the study to know which of these two agents contributes to faster recovery and hemodynamics.

\section{Hemodynamics}

We observed rise in pulse rate and systolic blood pressure after intubation. But this rise was within $20 \%$ of baseline value in both anesthetics. Similar results were observed in study of Ravi Jindal et al, Amandeep Kaur et al, Akkineni Lokesh et al $(1,2,5)$

Vallejo M C et al observed tachycardia in desflurane group during PACU admission post- operatively (6)

Rapid rise in concentration of desflurane will lead to activation of $\beta$ adrenergic receptors which causes tachycardia (9). Increase in heart rate and blood pressure during intubation probably due to sympathoadrenal stimulation during laryngoscopy

Hemodynamic parameters in terms of pulse, systolic and diastolic blood pressure were comparable in both the groups in our study.

\section{RECOVERY}

In our study we observed both early and intermediate recovery significantly faster in desflurane group as compared to sevoflurane group.

Nathanson et al found early recovery faster with desflurane and no difference in intermediate recovery end points. (3)

Eger EI in his study found quicker recovery for desflurane as compared to sevoflurane for a given duration of anesthesia. (10)
Juvin $\mathrm{P}$ and Dupont $\mathrm{J}$ in their studies observed faster early recovery with desflurane compared to sevoflurane even though the duration of surgery exceeded 2 hours. (7)

Akkineni Lokesh et al found rapid early recovery with desflurane as compared to sevoflurane (5).

Delayed recovery after sevoflurane would also be due to effect of its degradation product after prolonged anesthesia (10).

\section{CONCLUSION}

We concluded that both Desflurane and Sevoflurane provided stable intraoperative hemodynamics. However early and intermediate recovery was significantly faster in Desflurane group than Sevoflurane group.

\section{REFERENCES}

1. Ravi Jindal, Ved Prakash Kumra, Krishna Kumar Narani, Jayashree Sood. Comparison of maintenance and emergence characteristics after desflurane or sevoflurane in outpatient anesthesia. IJA 2011; 55:36-42.

2. Amandeep Kaur, Anil Kumar Jain, Aminder Sehgal, Jayashree Sood. Hemodynamics and early recovery characteristics of desflurane versus sevoflurane in bariatric surgery. J Anaesthesiol kin Pharmacol. 2013;29(1):36-40.

3. Nathanson MH, Fredman B, Smith I, White PF. Sevoflurane versus desflurane for outpatient anesthesia: A comparison of maintenance and recovery profiles. Anesth Analg 1995;81: 1186-90.

4. Akkineni Lokesh, Pragati Arora Trivedi, Rama Upadhyay. A comparative study of desflurane and sevoflurane for hemodynamic ability and postoperative outcome under general anesthesia. Int J Res Med; 4(2);133-136.

5. Vallejo MC, Sah N, Phelps AL, O'Donnell J, Romeo RC. Desflurane versus sevoflurane for laparoscopic gastroplasty in morbidly obese patients. J Clin Anesth. 2007 feb; 19(1): 3-8.

6. Gupta A, Stierer T, Zuckerman R, Sakima N, Parker SD, Fleisher LA. Comparison of recovery profile after ambulatory anesthesia with propofol, isoflurane, sevoflurane and desflurane: A systematic review. Anesth Analg 2004; 98:632-41.

7. Juvin P, Servin F, Giraud O, Desmonts JM. Emergence of elderly patients from prolonged desflurane, isoflurane, or propofol anesthesia. Anesth Analg 1997; 85:64751 .

8. Dupont J, Tavernier B, Ghosez Y, Durinck L, Thevenot A, Moktadir-Chalons N, et al. Recovery after anesthesia for pulmonary surgery: Desflurane, sevoflurane and isoflurane. Br JAnaesth 1999; 82:355-9.

9. Mukul Chandra Kapoor, Mahesh vakamudi. Desflurane revisited. Journal of Anesthesiology Clinical Pharmacology 2012; 28: 92-100.

10. Eger EI 2nd, Gong D, Koblin DD, Bowland T, Ionescu P, Laster MJ, et al. The effect of anesthetic duration on kinetic and recovery characteristics of desflurane versus sevoflurane, and on the kinetic characteristics of compound A, in volunteers. Anesth Analg 1998; 86:414-21. 